Jurnal Teknik Komputer AMIK BSI

Volume VI No.1 Januari 2020

P-ISSN 2442-2436, E-ISSN: 2550-0120

Akreditasi Ristekdikti, No: 21/E/KPT/2018

DOI: $10.31294 /$ jtk.v4i2

\title{
Sistem Informasi Restitusi Pengobatan Karyawan Dan Pensiun Pada Yakes-Telkom Jakarta
}

\author{
Nuzuliarini Nuris ${ }^{1}$ Ispandi $^{2}$, Nurmawati ${ }^{3}$ \\ ${ }^{1}$ Universitas Bina Sarana Informatika \\ e-mail: nuzuliarini.nzn@bsi.ac.id \\ ${ }^{2}$ STMIK Nusa mandiri Jakarta \\ e-mail: ispandi.ipd@nusamandiri.ac.id \\ ${ }^{3}$ Universitas Bina Sarana Informatika \\ e-mail: nurmawati315@ymail.com
}

\begin{tabular}{ccc}
\hline Diterima & Direvisi & Disetujui \\
$24-10-2019$ & $02-01-2020$ & $31-01-2020$ \\
\hline
\end{tabular}

\begin{abstract}
Abstrak - Pada saat ini setiap perusahaan mengingingkan dalam penyampaiaan informasi dapat dengan cepat dan tepat guna memberikan kontribusi yang optimal bagi perusahaan. Salah satunya adalah pada proses sistem restitusi. Restitusi menurut Yakes-Telkom adalah pemberian atau penggantian biaya berobat atas balas jasa karyawan tetap yang bekerja di PT.Telkom. Permasalahan yang sering timbul dalam Restitusi sejalan dengan proses biaya penggantian pengobatan yang masih menggunakan cara manual. Penerapan teknologi komputer seolah menjadi solusi terbaik dalam memecahkan permasalahan-permasalahan yang terjadi pada setiap sistem yang masih bersifat manual, serta tercapai suatu kegiatan yang efektif dan efisien dalam menunjang aktivitas yang terjadi pada perusahaan tersebut. Di harapkan dengan sistem informasi restitusi pengobatan karyawan dan pensiun pada Yakes-Telkom Jakarta dapat menunjang kegiatan serta meningkatkan kinerja dalam proses pengolahan restitusi. Setelah itu dilakukan uji coba sistem informasi restitusi pengobatan kepada karyawankaryawan dan di dapat bahwa $73 \%$ sistem tersebut dapat membantu dalam mempercepat mereka dalam pelaksanaan kegiatan.
\end{abstract}

Kata Kunci: Perancangan sistem informasi, sistem restitusi pengobatan

\begin{abstract}
At this time every company wants in the delivery of information can be quickly and precisely in order to provide optimal for the company. One of them is in the process of restitution system. Restitution, according to Yakes-Telkom, is a provider or delivery fee for employees at PT Telkom. Problems that often arise in Restitution with the cost of the replacement process that still uses the manual method. The application of computer technology is the best solution in solving problems that occur on every system that is still manual, as well as improving activities that are effective and efficient in supporting activities that occur at the company. It is recognized that the care and retirement restitution information system at Yakes-Telkom Jakarta can support activities and improve performance in the process of restitution processing. After the trial, the maintenance restitution information system for employees and can $73 \%$ of the system can assist in accelerating their implementation of activities.
\end{abstract}

Keywords: Information system design, treatment restitution system

\section{PENDAHULUAN}

Teknologi saat ini menuntut kecepatan dan ketepatan dalam mengolah data serta informasi yang cepat dan akurat, maka penggunaan sistem komputer akan membantu meningkatkan pelaksanaan kegiatan pekerjaan, terutama dalam pengolahan data yang akan menghasilkan informasi yang cepat dan akurat, tanpa menyita banyak waktu, tenaga dan biaya.

Saat ini banyak perusahaan yang telah menyediakan berbagai fasilitas yang dapat meningkatkan kinerja para karyawan. Yang mana setiap perusahaan selalu memberikan layanan terbaik bagi kesejahteraan karyawan, salah satunya adalah jaminan kesehatan. (Supriyatna, 2016:2) menyatakan bahwa "Salah satu cara meningkatkan status kesehatan adalah meningkatkan pelayanan kesehatan”. Kesehatan merupakan kunci utama yang harus dimiliki oleh setiap manusia, tanpa adanya kesehatan manusia tidak dapat beraktivitas dan menyelesaikan pekerjaan dengan baik, hal ini dapat mengakibatkan tingkat produktivitas menurun.

Yakes-Telkom adalah sebuah yayasan kesehatan yang didirikan oleh PT.Telkom untuk para karyawan 
dan pensiunan serta keluargannya. Yakes-Telkom sendiri menggunakan Managed Care, yaitu jenis asuransi kesehatan yang mengatur penyediaan dan pembiayaan perawatan kesehatan yang bergantung pada kendali mutu berupa pelayanan yang efisien serta memberi kepuasan pada pasien dan kendali biaya berupa keterkaitan dengan penghematan biaya pengeluaran pasien sendiri. Dengan Menggunakan sistem Managed Care, Yakes-Telkom termasuk pelayanan yang komprehensif karena mengandung unsur preventif, promotif, kuratif, serta rehabilitatif yang membantu pelayanan keseahatan untuk para karyawan dan pensiun Telkom. Salah satunya adalah restitusi. Dimana sebuah fasilitas pemberian atau penggantian biaya berobat baik karyawan aktif maupun pensiunan, yang prosesnya melalui unit kerja masing-masing area.

Pada Yakes-Telkom Jakarta bagian yang bergerak menangani restitusi pengobatan adalah ADM Support yang berada di Tempat Pelayanan Kesehatan Khusus (TPKK) di Percetakan Negara. Dimana dalam proses penginputan data belum menggunakan aplikasi khusus sehingga mengakibatkan keterlambatan pengiriman data, hal ini menjadi hambatan bagi karyawan dan pensiunan dalam mengetahui informasi mengenai restitusi yang diajukan. Oleh karena itu, penulis akan merancang sistem informasi berbasis web yang dapat mempermudah kerja ADM Support dalam menginput data.

(Hendini 2016:108): Website atau situs dapat diartikan sebagai kumpulan halaman-halaman yang berasal dari file-file berisi bahasa pemrograman yang saling berhubungan digunakan untuk menampilkan informasi, gambar bergerak dan tidak bergerak, suara dan atau gabungan dari semuanya itu baik yang bersifat statis maupun dinamis.

(Anggraeni \& Irvani, 2017) Sistem informasi adalah suatu sistem dalam suatu organisasi yang mempertemukan kebutuhan pengolahan transaksi harian yang mendukung fungsi operasi organisasi yang bersifat manajerial dengan kegiatan strategi dari suatu organisasi untuk dapat menyediakan kepada pihak luar tertentu dengan informasi yang diperlukan untuk pengambilan keputusan.

Sistem Informasi restitusi pada Yakes-Telkom berbasis web yang tujuannya meningkatkan kinerja proses pengelolaan restitusi.

Sistem yang dirancang menggunakan activity diagram dan use case. (Rosa \& Shalahudin, 2016), "Diagram aktivitas atau activity diagram menggambarkan workflow (aliran kerja) atau aktivitas dari sebuah sistem atau proses bisnis atau menu yang ada pada perangkat lunak". Activity diagram menggambarkan aktivitas sistem bukan apa yang dilakukan aktor, jadi aktivitas yang dapat dilakukan oleh sistem.

(Rosa \& Shalahudin, 2016), Use case diagram merupakan pemodelan untuk kelakuan (behavior) sistem informasi yang dibuat. Use case mendepskripsikan sebuah interaksi antara satu atau lebih actor dengan sistem informasi yang akan dibuat. Untuk merancang database digunakan model Entity Relation Diagram (ERD).

(Puspitasari, 2016) Entity Relationship Diagram (ERD) adalah suatu rancangan atau bentuk hubungan suatu kegiatan di dalam sistem yang berkaitan langsung dan mempunyai fungsi di dalam proses tersebut. ERD adalah suatu pemodelan dari basis data relasional yang didasarkan atas persepsi di dalam dunia nyata, dunia ini senantiasa terdiri dari sekumpulan objek yang saling berhubungan antara satu dengan yang lainnya. Suatu objek disebut entity dan hubungan yang dimilikinya disebut relationship.

\section{METODOLOGI PENELITIAN}

Metode yang digunakan pada pengembangan perangkat lunak ini menggunakan metode waterfall. Model ini lebih dikenal dengan model linear sequential, yang merupakan model klasik bersifat sistematis, yang digunakan sebagai acuan dalam mengembangkan suatu proyek yang inovatif dan kompleks. Menurut (Rosa \& Shalahudin, 2016), Metode yang digunakan pada pengembangan perangkat lunak ini menggunakan model waterfall yang terbagi dalam lima tahapan, yaitu :

1. Analisa kebutuhan perangkat lunak

Analisa ini bertujuan untuk mengumpulkan data-data yang berkaitan dengan sistem penjualan dan pembelian. Analisa kebutuhan terdiri dari analisa kebutuhan fungsional (fungsi sistem) dan analisa kebutuhan nonfungsional (pengguna sistem dan alat yang diperlukan dalam perancangan sistem). Tujuan dari analisa ini untuk mendapatkan informasi dasar seputar sistem yang diterapkan dan digunakan sebagai dasar dalam perancangan sistem.

2. Desain

Setelah mendapatkan data-data dari analisa, maka masuk pada tahap desain. Penulis merancang sistem yang terdiri dari rancangan basis data, rancangan Hierarchy Input Process Output (HIPO) dan pemodelan antara muka.

3. Pembuatan Kode Program

Hasil dari tahap ini adalah program komputer sesuai dengan desain yang telah dibuat pada tahap desain yang ditranslasikan kedalam program perangkat lunak.

4. Pengujian

Untuk meminimalisir kesalahan (error) dan keluaran yang dihasilkan sesuai dengan yang diinginkan. Maka pengujian difokuskan pada perangkat lunak secara segi logik dan fungsioanal memastikan bahwa semua bagian sudah diuji.

5. Pendukung (support) atau pemeliharaan (maintenance) 
Tahap pendukung atau pemeliharaan dapat mengulangi proses pengembangan mulai dari analisis spesifikasi untuk perubahan perangkat lunak yang sudah ada, tetapi tidak untuk membuat perangkat lunak yang baru. Agar tidak mengalami perubahan ketika sudah dikirimkan ke user karena adanya kesalahan yang muncul dan tidak terdeteksi saat pengujian atau perangkap lunak harus beradaptasi dengan lingkungan baru.

\section{HASIL DAN PEMBAHASAN}

Sistem informasi restitusi pengobatan karyawan dan pension pada Yakes-Telkom Jakarta yang di lakukan masih secara sederhana dan sering terjadi kendala.
Adapun permasalahan yang menjadi penghambat jalannya kegiatan, keberhasilan dan tujuan yang diterapkan perusahaan. Permasalahan sistem restitusi pengobatan pada Yakes-Telkom Jakarta adalah sebagai berikut :

a. Dalam proses penginputan data karyawan dan pensiunan yang mengajukan restitusi belum menggunakan aplikasi khusus sehingga memerlukan waktu dalam penginputan data.

b. Sering terjadi kesalahan dalam pencarian berkas-berkas data karyawan dan pensiunan sehingga membutuhkan waktu yang lama, oleh karena itu membutuhkan database agar pencarian berkas-berkas mudah ditemukan dan tersimpan rapi.

\section{Perancangan Use Case Diagram}

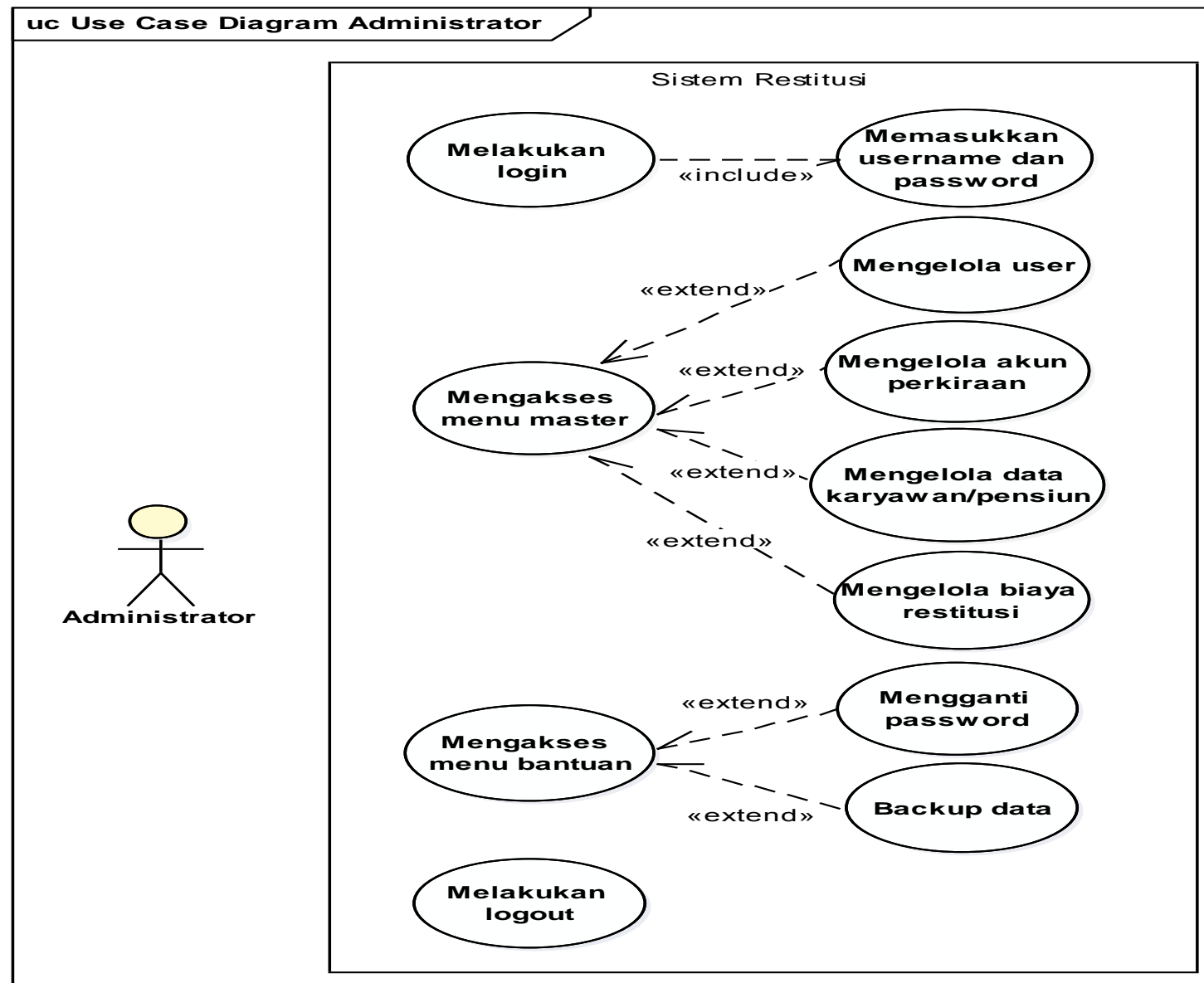

Gambar 1. Use Case Diagram Administrator Sistem Restitusi 


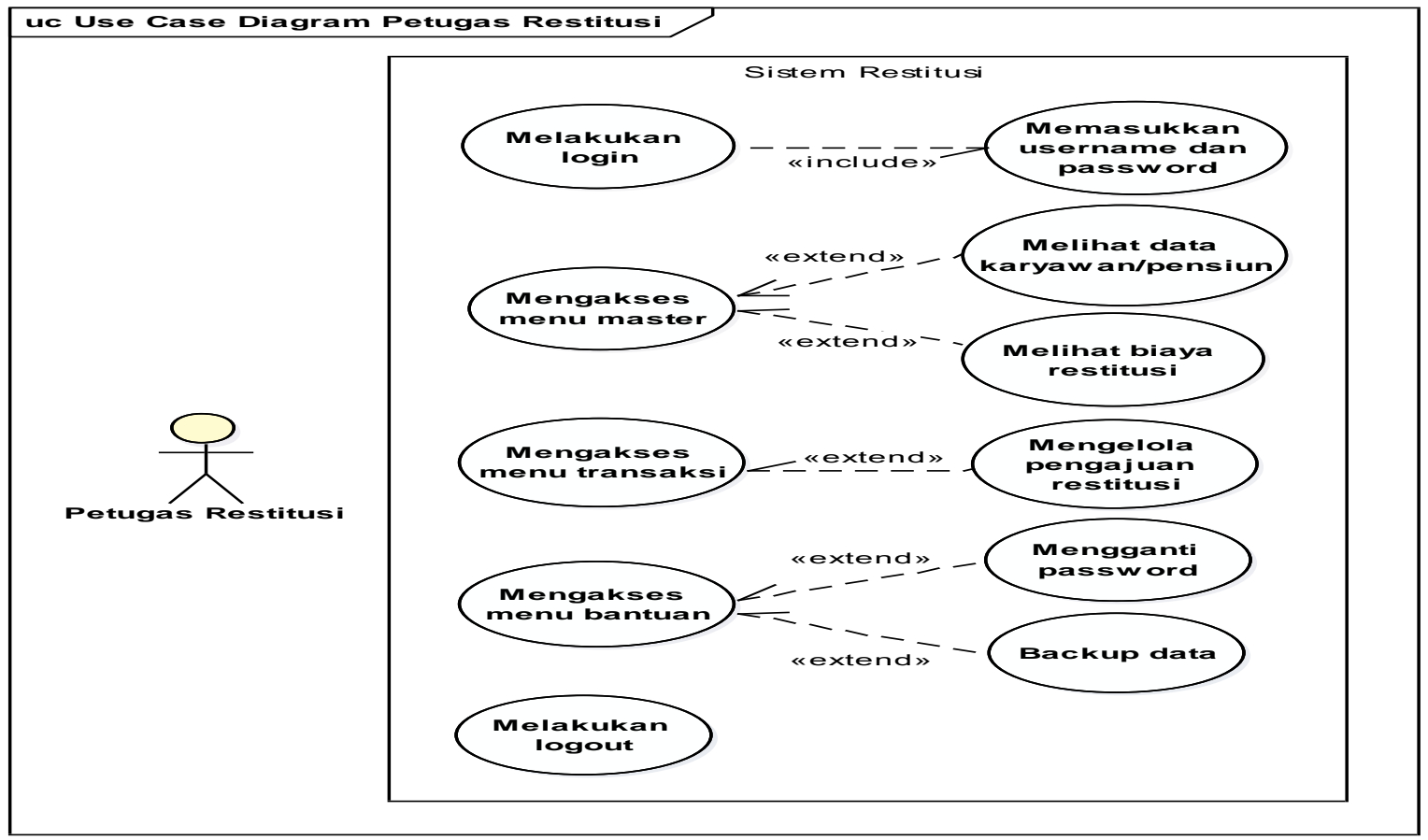

Gambar 2. Use Case Diagram Petugas Restitusi Sistem Restitusi

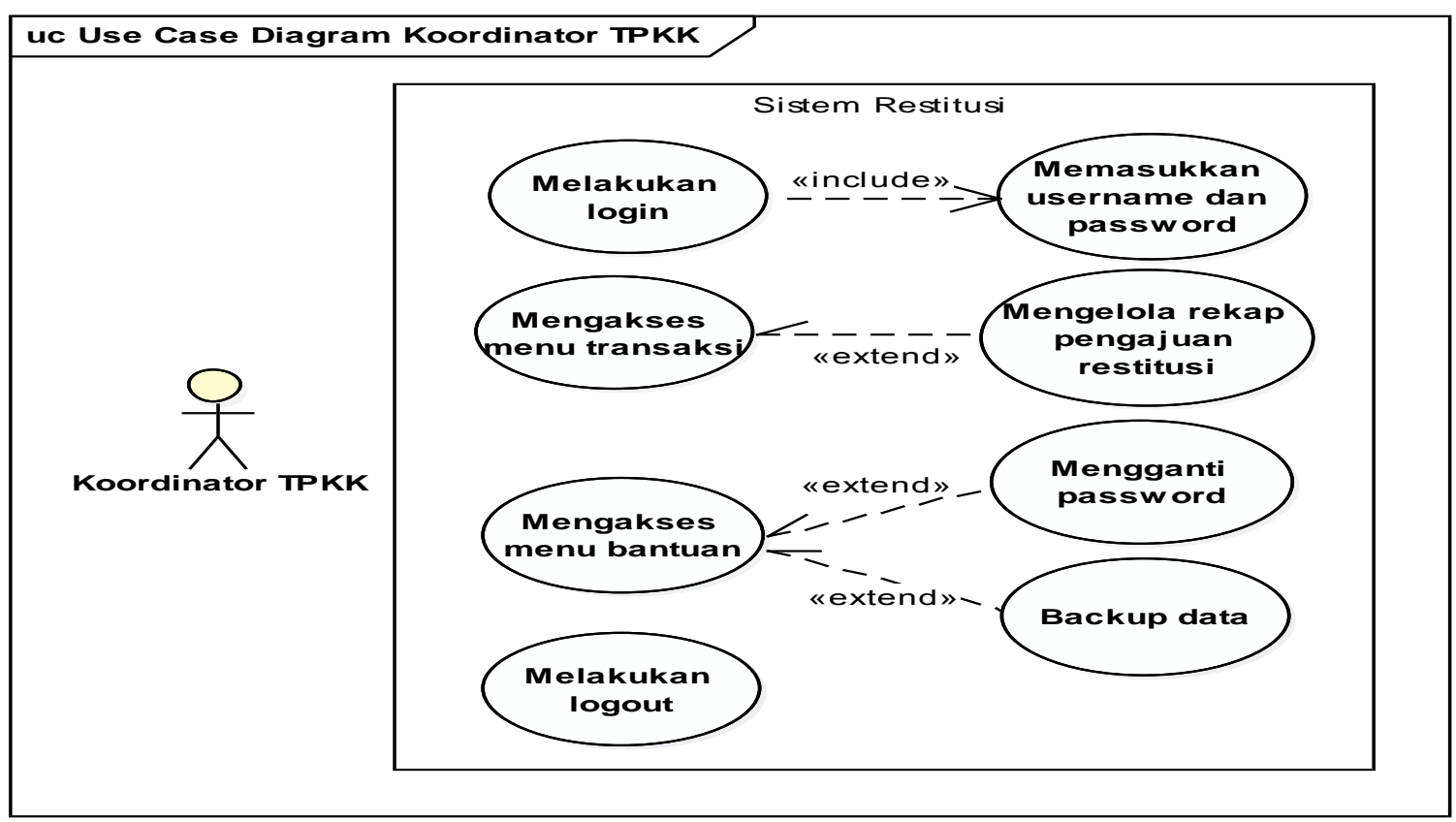

Gambar 3. Use Case Diagram Koordinator TPKK Sistem Restitusi 
2. Activity Diagram

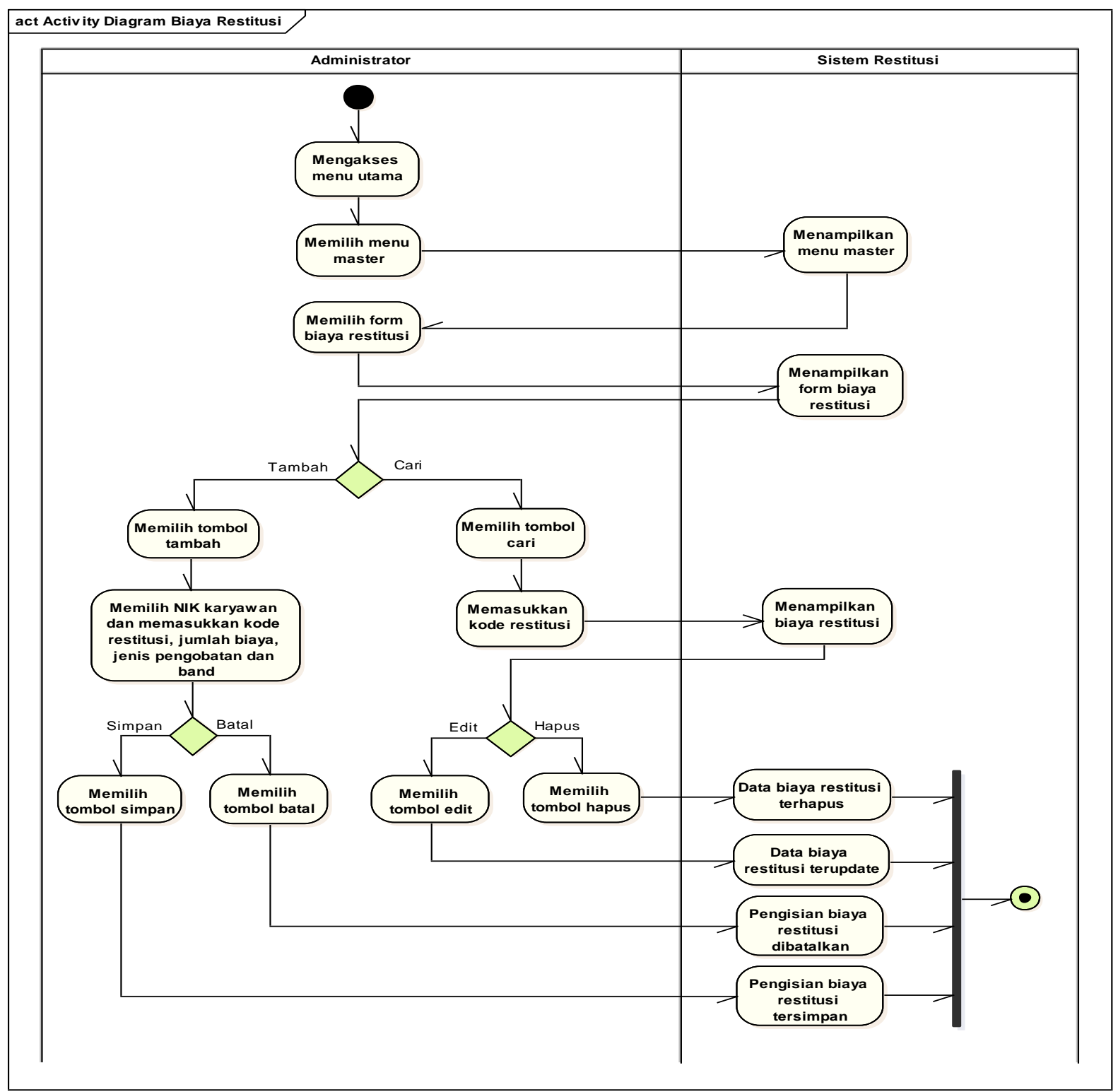

Gambar 4. Activity Diagram Administrator Mengelola Biaya Restitusi 


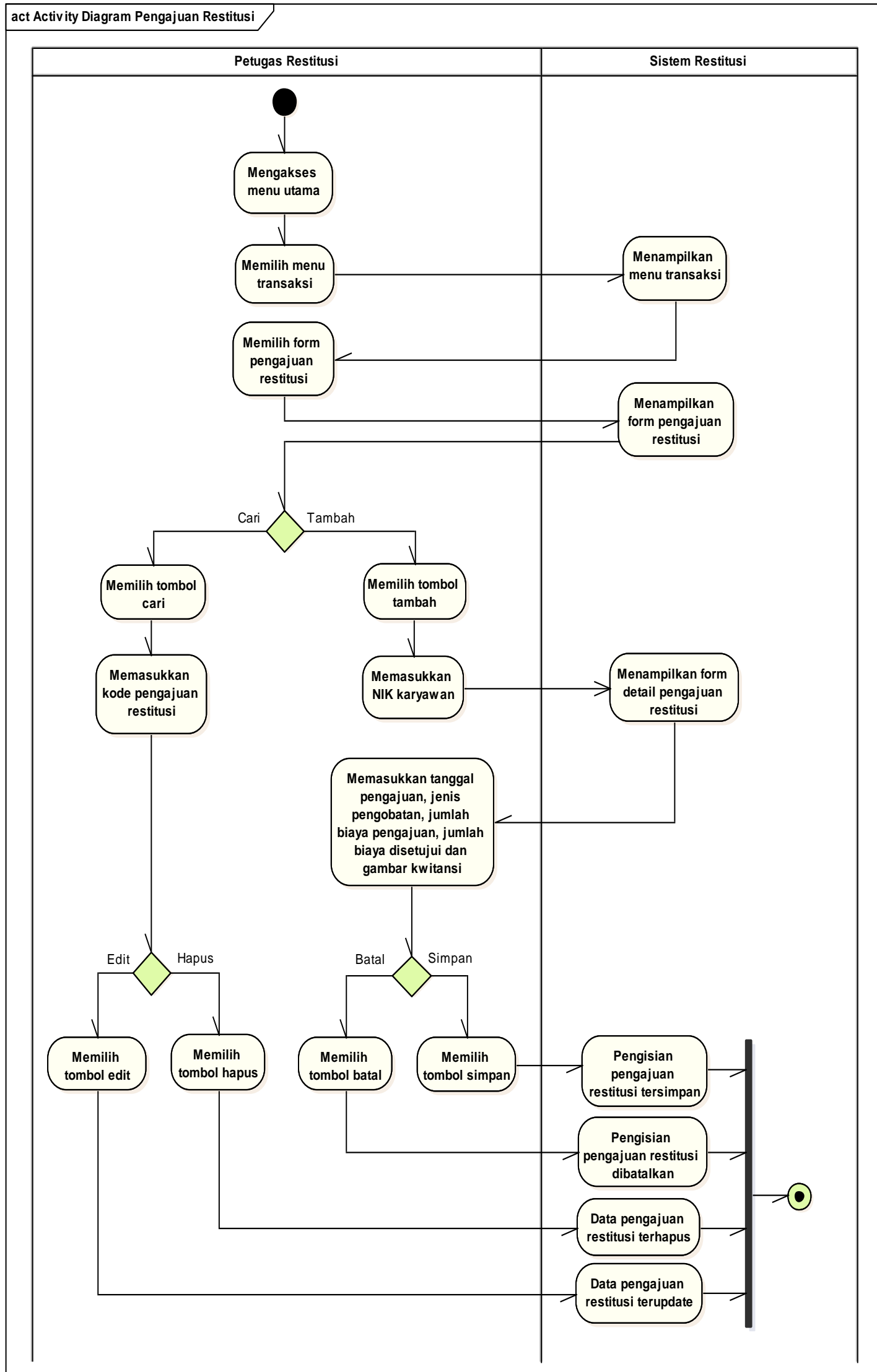

Gambar 5. Activity Diagram Petugas Restitusi Mengelola Pengajuan Restitusi 


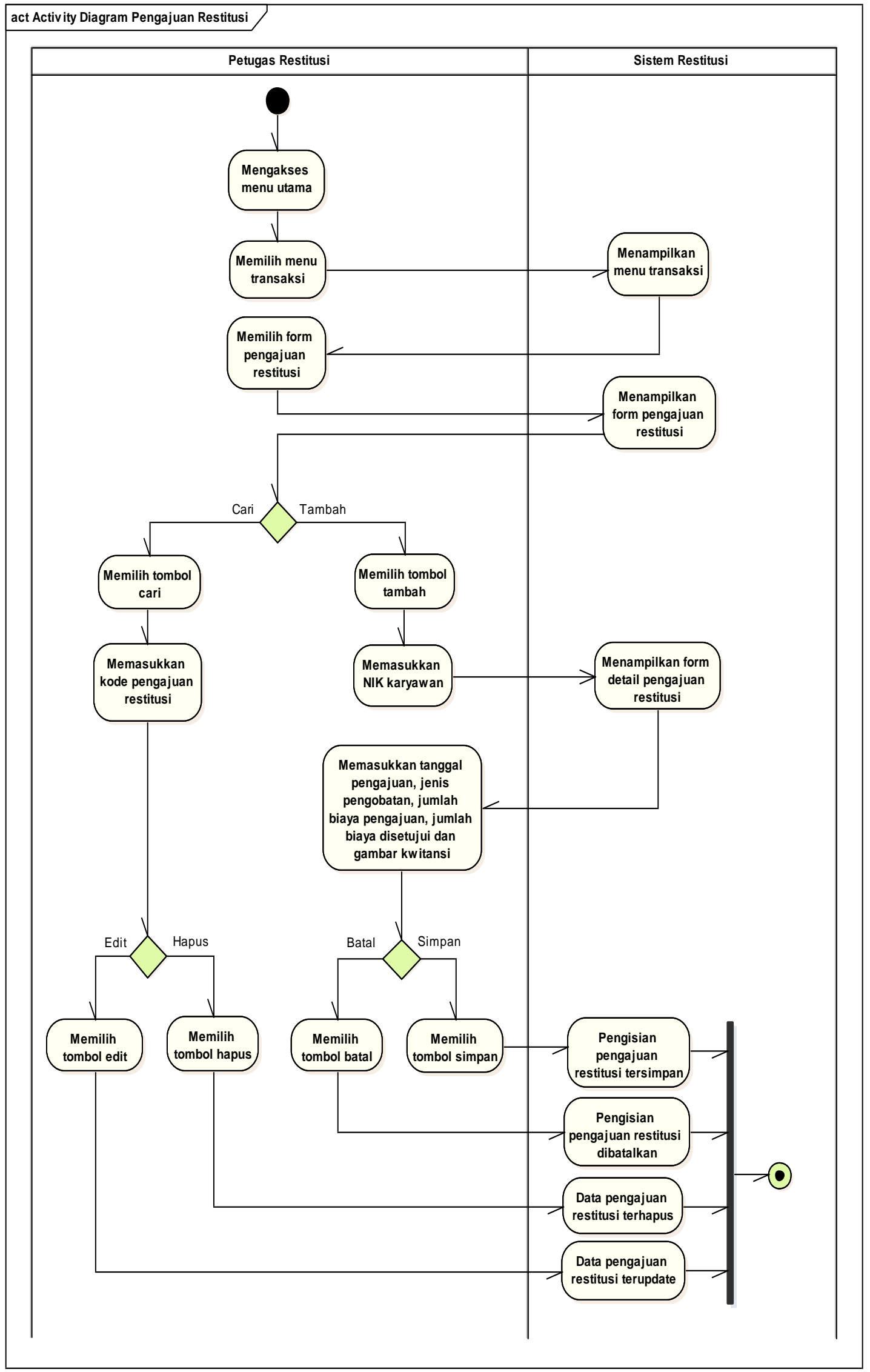

Gambar 6. Activity Diagram Petugas Restitusi Mengelola Pengajuan Restitusi 
3. Entity Relationship Diagram (ERD)

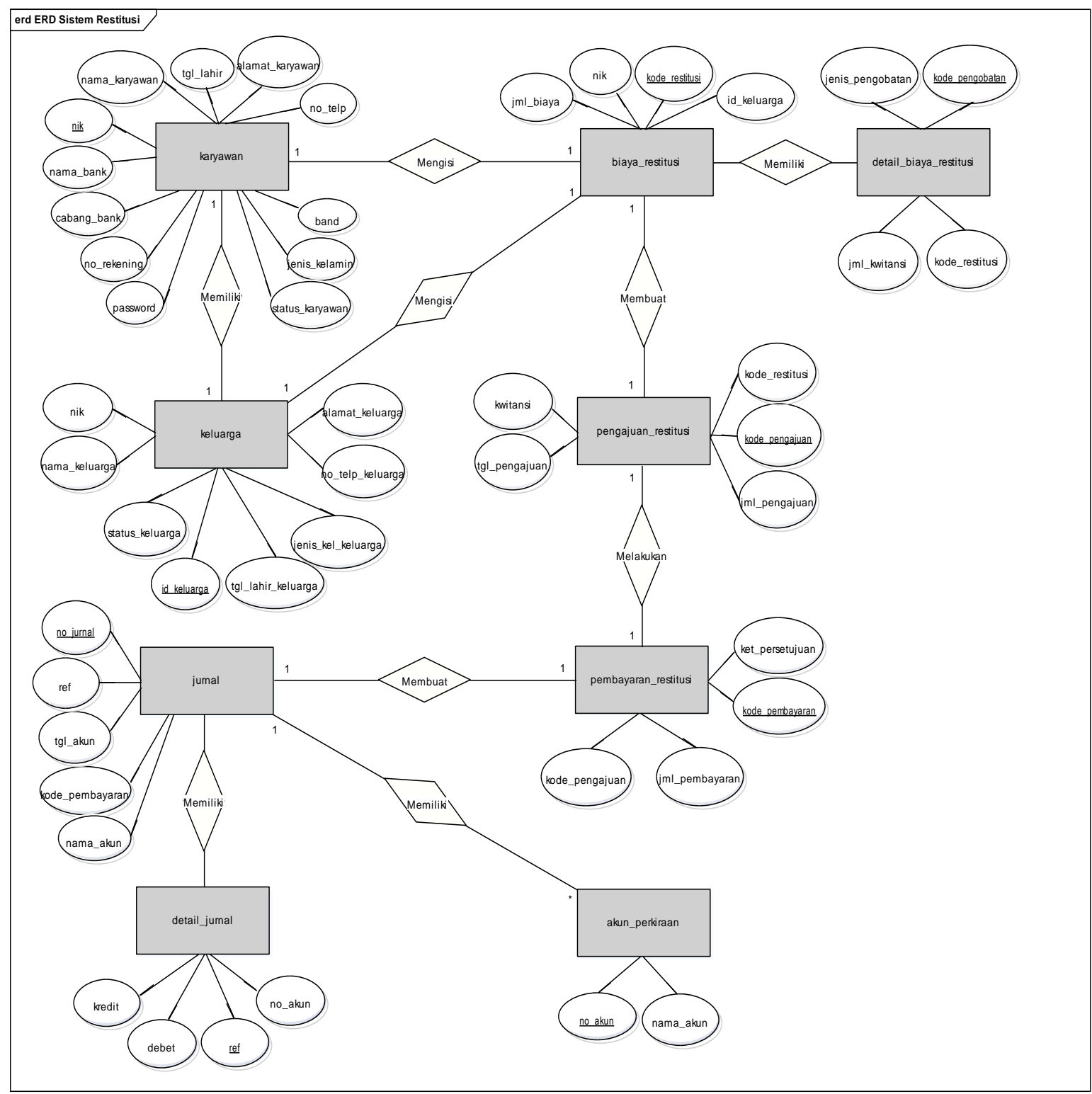

4. Rancangan Tampilan

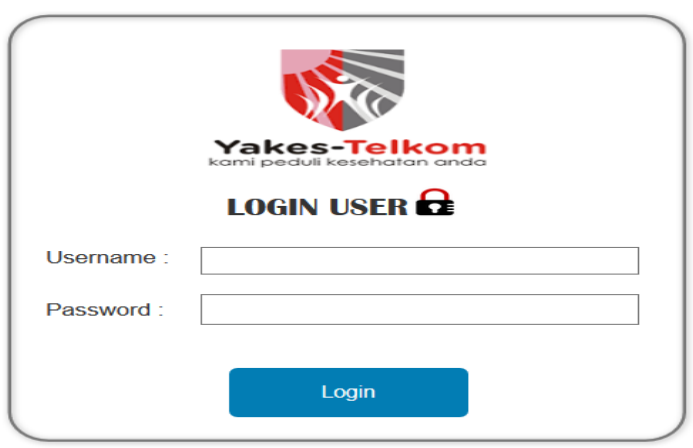

Gambar 8. Tampilan Form Halaman Login

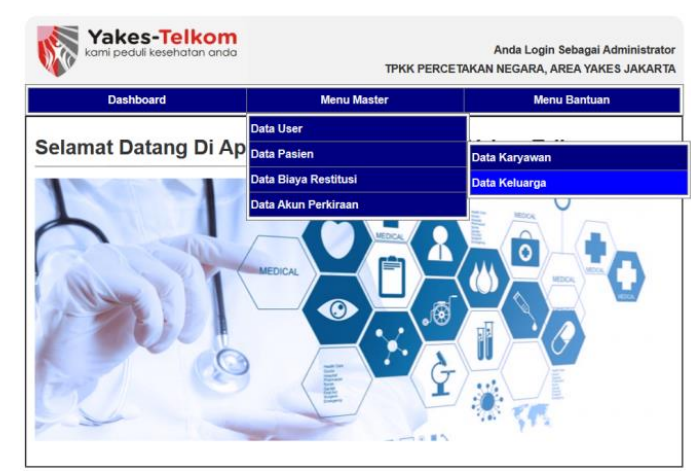

Gambar 9. Tampilan Menu Utama Administrator 


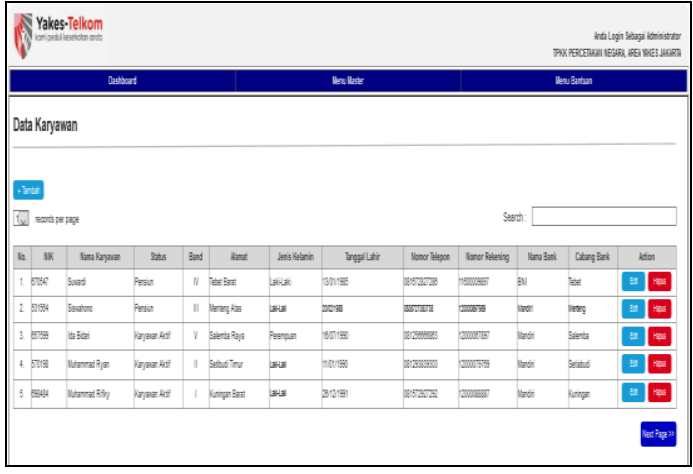

Gambar 10. Form Data Karyawan

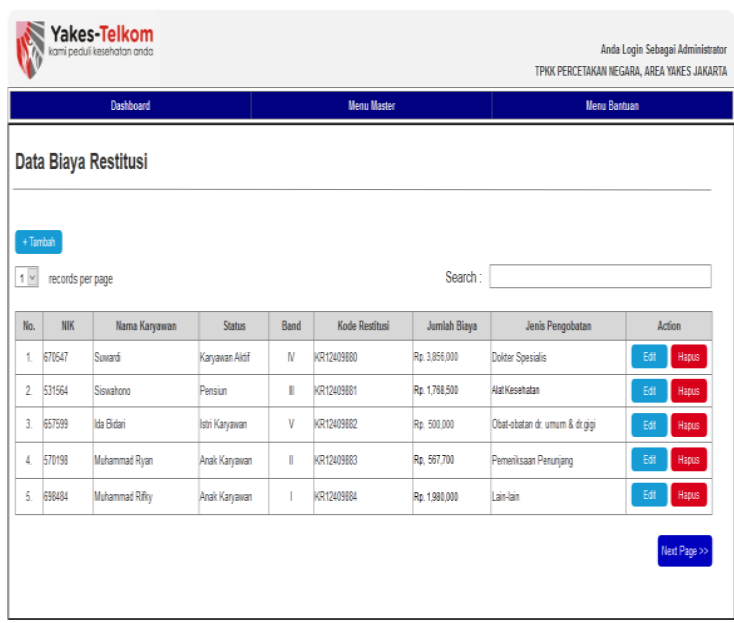

Gambar 11. Form Biaya Restitusi

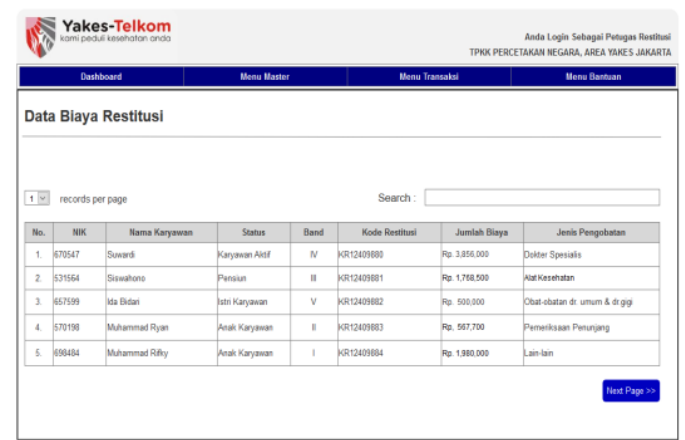

Gambar 12. Melihat Biaya Restitusi

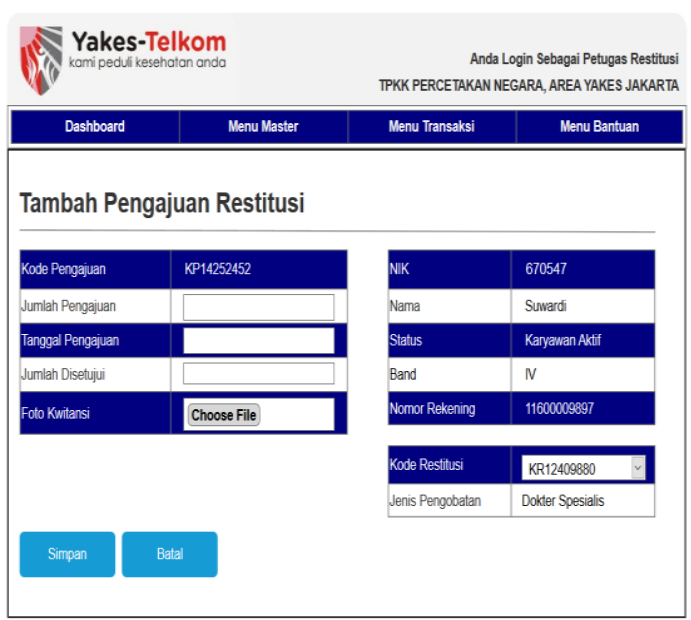

Gambar 13. Tambah Pengajuan RetsitusI

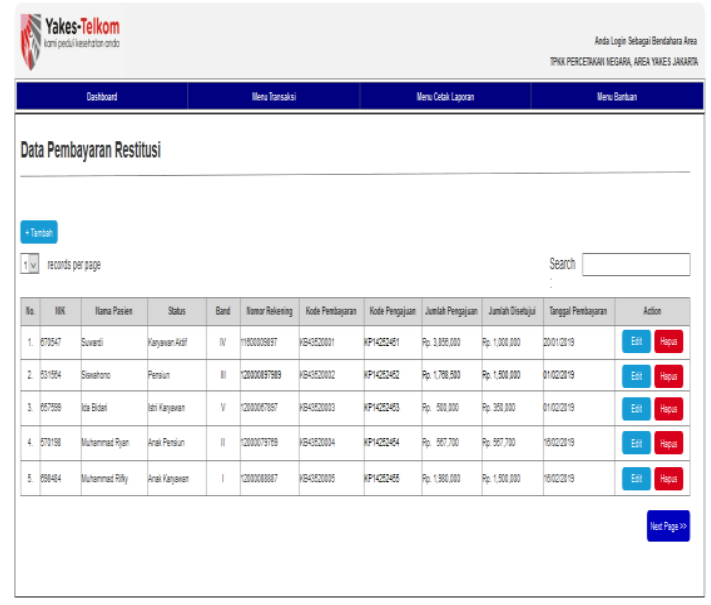

Gambar 14. Form Pembayaran Restitusi

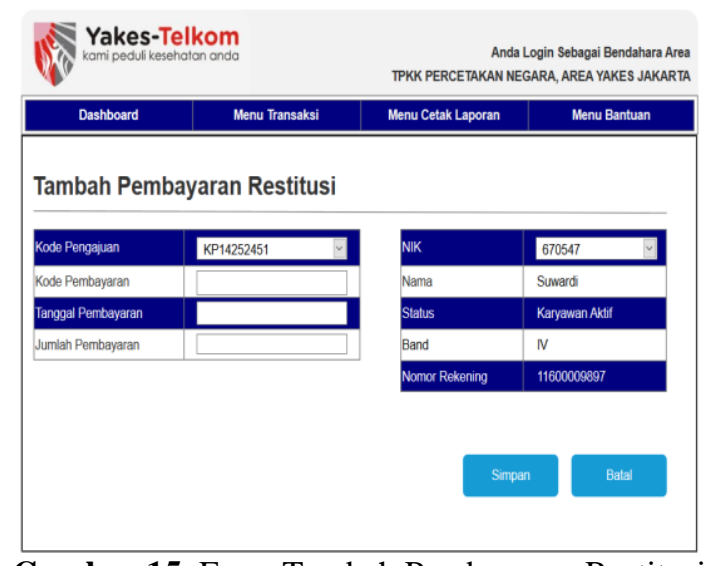

Gambar 15. Form Tambah Pembayaran Restitusi

\section{KESIMPULAN}

Dalam pengusulan solusi dengan menggunakan sistem yang terkomputerisasi, maka penulis telah mengambil beberapa kesimpulan sebagai berikut (1). Pada awalnya dalam proses restitusi pada YakesTelkom Jakarta belum menggunakan aplikasi khusus, namun penulis membuat sistem baru yang terkomputerisasi untuk mempercepat proses penginputan data dan pembuatan laporan. (2) Sering terjadi kesalahan dalam pencarian berkas-berkas data karyawan/pensiun sehingga membutuhkan waktu yang lama, oleh sebab itu membutuhkan database agar pencarian berkas-berkas mudah ditemukan dan tersimpan dengan rapi. (3) )Membangun sistem informasi restitusi yang memfasilitasi pembuatan data master, data transaksi, mencetak laporan dan membuat menu bantuan sehingga mengurangi masalah human error. (4) Uji coba sistem informasi restitusi pengobatan yang dilakukan kepada karyawan-karyawan dan di dapat bahwa 73\% sistem tersebut dapat membantu dalam mempercepat mereka dalam pelaksanaan kegiatan. 


\section{REFERENSI}

Anggraeni, E. Y., \& Irviani, R. (2017). Pengantar Sistem Informasi. (E. Risanto, Ed.) (1st ed.). Yogyakarta: CV ANDI OFFSET.

Buana, I. K. S. (2014). Jago Pemrograman PHP. Jakarta: Dunia Komputer.

Fridayanthie, E. W., \& Mahdiati, T. (2016). Rancang Bangun Sistem Informasi Permintaan Atk Berbasis Intranet. Jurnal Khatulistiwa Informatika, IV(2), 31-48.

Hendini, A. (2016). Pemodelan Uml Sistem Informasi Monitoring Penjualan Dan Stok Barang (Studi Kasus: Distro Zhezha Pontianak). Jurnal Khatulistiwa Informatika, IV(2), 107-116.

Hidayatullah, P., \& Kawistara, J. K. (2017). Pemrograman Web Edisi Revisi. Bandung: Informatika.

Hutahaean, J. (2014). Konsep Sistem Informasi (1st ed.). Yogyakarta: Deepublish.
Indrajani. (2015). Database Design (Case Study All in One). Jakarta: PT. Elex Media Komputindo.

Krisianto, A. (2014). Internet Untuk Pemula. Jakarta: Elex Media Komputindo.

Mandar, R. (2017). Solusi Tepat Menjadi Pakar Adobe Dreamwaver CS6. Jakarta: PT. Elex Media Komputindo.

Nugroho, A. S. (2016). Analisis dan Perancangan Sistem Informasi. Yogyakarta: Trans Tekno.

Puspitasari, D. (2016). Sistem Informasi Perpustakaan Sekolah Berbasis Web. Jurnal Pilar Nusa Mandiri, XII(2), 227-240.

Rosa, A. ., \& Shalahudin, M. (2016). Rekayasa Perangkat Lunak Terstruktur dan Berorientasi Objek (IV). Bandung: Informatika.

Supriyatna, A. (2016). Pemeliharaan Kesehatan Masyarakat Berbasis Web. Paradigma, XVIII(2), 1-10. 